\title{
Promotion of Physical Activity in Older People Using mHealth and eHealth Technologies: Rapid Review of Reviews
}

\author{
Lisa McGarrigle ${ }^{1,2}, \mathrm{PhD}$; Chris Todd ${ }^{1,2,3,4,5}, \mathrm{PhD}$ \\ ${ }^{1}$ School of Health Sciences, Faculty of Biology, Medicine and Health, The University of Manchester, Manchester, United Kingdom \\ ${ }^{2}$ Manchester Academic Health Science Centre, Manchester, United Kingdom \\ ${ }^{3}$ National Institute for Health Research Older People and Frailty Policy Research Unit, School of Health Sciences, Faculty of Biology, Medicine and \\ Health, The University of Manchester, Manchester, United Kingdom \\ ${ }^{4}$ Manchester University NHS Foundation Trust, Manchester, United Kingdom \\ ${ }^{5}$ National Institute for Health Research Applied Research Collaboration-Greater Manchester, School of Health Sciences, Faculty of Biology, Medicine \\ and Health, The University of Manchester, Manchester, United Kingdom
}

\section{Corresponding Author:}

Chris Todd, $\mathrm{PhD}$

School of Health Sciences

Faculty of Biology, Medicine and Health

The University of Manchester

Oxford Road

Manchester, M13 9PL

United Kingdom

Phone: 441613067865

Email: chris.todd@manchester.ac.uk

\section{Abstract}

Background: Older people are at increased risk of adverse health events because of reduced physical activity. There is concern that activity levels are further reduced in the context of the COVID-19 pandemic, as many older people are practicing physical and social distancing to minimize transmission. Mobile health (mHealth) and eHealth technologies may offer a means by which older people can engage in physical activity while physically distancing.

Objective: The objective of this study was to assess the evidence for mHealth or eHealth technology in the promotion of physical activity among older people aged 50 years or older.

Methods: We conducted a rapid review of reviews using PRISMA (Preferred Reporting Items for Systematic Reviews and Meta-Analyses) guidelines. We searched for systematic reviews published in the English language in 3 electronic databases: MEDLINE, CINAHL Plus, and Scopus. Two reviewers used predefined inclusion criteria to select relevant reviews and extracted data on review characteristics and intervention effectiveness. Two independent raters assessed review quality using the AMSTAR-2 tool.

Results: Titles and abstracts $(\mathrm{n}=472)$ were screened, and 14 full-text reviews were assessed for eligibility. Initially, we included 5 reviews but excluded 1 from the narrative as it was judged to be of critically low quality. Three reviews concluded that mHealth or eHealth interventions were effective in increasing physical activity. One review found that the evidence was inconclusive.

Conclusions: There is low to moderate evidence that interventions delivered via mHealth or eHealth approaches may be effective in increasing physical activity in older adults in the short term. Components of successful interventions include self-monitoring, incorporation of theory and behavior change techniques, and social and professional support.

(J Med Internet Res 2020;22(12):e22201) doi: $\underline{10.2196 / 22201}$

\section{KEYWORDS}

physical activity; mHealth; eHealth; app; accelerometer; pedometer; technology; COVID-19 


\section{Introduction}

Older people engage in physical activity less regularly than younger age groups, and participation progressively decreases with age [1]. Inactivity is associated with frailty and adverse health outcomes in middle-aged to older adults [2], with sedentary people aged $>50$ years having twice the risk of death compared to those with the highest levels of physical activity [3]. The benefits of engagement in physical activity in older age are vast. Regular activity of moderate intensity (150 minutes per week) is consistently associated with reduced risk of chronic diseases [4], cognitive decline [5], and mortality [6]. Exercise programs that emphasize improving strength and balance reduce falls in older people [7].

During 2020, as a result of lockdown and physical or social distancing measures introduced in an effort to reduce coronavirus (COVID-19) transmission, there is concern that older people are at risk of further reduced activity levels and consequently, at increased risk of adverse health events. One approach to promoting activity that has gained particular traction over recent years is the use of exercise and activity mobile apps, tracking devices, and tablet or computer-based interventions. Physical activity interventions delivered via apps on mobile or wireless devices, such as smartphones or tablets, are collectively referred to as mobile health (mHealth) interventions [8]. Interventions delivered or enhanced through the internet and related technologies (eg, websites, wearable motion sensing devices) are referred to as eHealth interventions [9]. These kinds of interventions may offer a cost-effective and accessible way to promote activity in older populations as an alternative to face-to-face sessions. A recent review and meta-analysis of randomized controlled trials (RCTs) across a range of age groups found that mHealth interventions increased physical activity levels and reduced sedentary behavior [10]. mHealth and eHealth approaches may be feasible and acceptable in older populations [11], with an increasing number of older adults accessing the internet in recent years [12]. The effectiveness of these kinds of interventions in older people has been widely investigated, but a clear consensus on their usefulness in increasing physical activity is lacking. The objective of this review was to summarize the evidence from systematic reviews of the effectiveness of mHealth and eHealth approaches on physical activity in older people.

\section{Methods}

To provide an overview the evidence on the use of mHealth and eHealth technologies in the promotion of physical activity in older people, we undertook a rapid review of reviews $[13,14]$ and followed guidance for conducting overviews [15]. We followed a standard protocol in accordance with the PRISMA (Preferred Reporting Items for Systematic Reviews and Meta-analysis) statement, adjusted for rapid review and "review of reviews" methodologies.

\section{Search Strategy}

Database searches were conducted in MEDLINE (Ovid), CINAHL Plus (EBSCO), and Scopus (Elsevier) for reviews focusing on mHealth or eHealth technologies in the promotion of physical activity in older people. All searches were conducted in May 2020 (see Multimedia Appendix 1 for the search strategy).

\section{Inclusion and Exclusion Criteria}

As this was a rapid review, included papers were restricted to full-text availability in the English language. No restrictions were made for year of publication nor for study designs included in the reviews in order to get a complete picture of the effectiveness of the interventions.

Reviews were included if they used systematic review techniques to review the use of mHealth or eHealth technologies for the promotion of physical activity among older adults; the mHealth or eHealth interventions targeted generally healthy older people aged $\geq 50$ years; and outcomes were related to levels of physical activity, exercise, fitness, or reduction in sedentary behavior, measured using self-report instruments, measurement devices (eg, accelerometers, pedometers), or energy expenditure (eg, metabolic equivalents of task [METs]).

Reviews were excluded if they did not use systematic review techniques, did not focus on older populations aged $\geq 50$ years, focused on mHealth or eHealth interventions only in disease-specific samples or in people with chronic conditions (eg, Parkinson's disease, stroke, diabetes, cancer, depression, obesity), or focused solely on technology interventions that required equipment other than body-worn sensors (eg, smartwatches) or smartphone-type devices, which are costly and unlikely to be easily accessible to older people (ie, we excluded exergaming, virtual reality gaming, smart homes, robotics).

Reviews in which only a minority of the included studies met the described criteria (ie, only some of the included studies focused on older adults, only some of the included studies focused on generally healthy populations, the majority of technologies were outside our inclusion criteria) were considered for inclusion only if it was agreed between both authors independently that they provided insight into the effectiveness of mHealth or eHealth interventions. In order to be accepted for inclusion, the review had to present analysis for the subset of relevant studies included in the review that fulfilled our inclusion criteria, or it had to be possible to derive estimates of effect for the subset of relevant studies included in the review from data presented.

\section{Screening and Data Extraction}

Following identification and removal of duplicates, we exported all citations from Zotero (version 5.0.85) [16] into Rayyan [17], a web application to expedite the blinded screening process. Titles, abstracts, and potentially relevant full texts were screened independently by both authors, and any disagreements were resolved by discussion. Both authors independently used a tailored, predefined, data extraction form to record relevant review characteristics (Multimedia Appendix 2 for data extracted). Descriptions of the included reviews were tabulated for clarity. 


\section{Data Analysis}

Depending on heterogeneity of interventions and outcome measurements and summary measures used across included systematic reviews, we undertook a meta-analysis [18]. If the meta-analysis was not possible, we present pooled summary data without further analysis.

\section{Quality Assessment}

Included reviews were subjected to quality assessment using AMSTAR-2 [19,20]. AMSTAR-2 is used to generate an overall rating of "high," "moderate," "low," or "critically low." Both authors conducted the assessments independently and then discussed ratings to agree consensus. Assessments of study quality or risk of bias reported in the included systematic reviews are presented (Table 1).

Table 1. Summary of review characteristics and quality assessment.

\begin{tabular}{|c|c|c|c|c|c|c|}
\hline $\begin{array}{l}\text { Author } \\
\text { (year) }\end{array}$ & Type of review & $\begin{array}{l}\text { Number of included } \\
\text { studies and designs }\end{array}$ & Aim & Population (n) & $\begin{array}{l}\text { AMSTAR-2 } \\
\text { Rating }\end{array}$ & $\begin{array}{l}\text { Quality of } \\
\text { evidence }^{\mathrm{a}}\end{array}$ \\
\hline $\begin{array}{l}\text { Cooper et al } \\
\text { (2018) [21] }\end{array}$ & $\begin{array}{l}\text { Systematic review } \\
\text { and meta-analysis }\end{array}$ & $\begin{array}{l}9 \mathrm{RCTs}^{\mathrm{b}} \text { ( } 8 \text { included } \\
\text { in meta-analysis) }\end{array}$ & $\begin{array}{l}\text { To investigate how different } \\
\text { wearable activity trackers } \\
\text { impact } \mathrm{PA}^{\mathrm{c}} \text { levels }\end{array}$ & $\begin{array}{l}\text { Older adults aged } \\
\geq 65 \text { years }(939)\end{array}$ & Moderate & $\begin{array}{l}\text { Cochrane Risk of } \\
\text { Bias Tool: high } \\
\text { risk }(n=6) \text {, unclear } \\
\text { risk }(n=2) \text {, low risk } \\
(n=1)\end{array}$ \\
\hline $\begin{array}{l}\text { Jonkman et al } \\
(2018)^{\mathrm{d}}[22]\end{array}$ & $\begin{array}{l}\text { Narrative review, } \\
\text { but systematic ap- } \\
\text { proach }\end{array}$ & 12 RCTs & $\begin{array}{l}\text { To provide an overview of } \\
\text { the effectiveness of eHealth } \\
\text { interventions in increasing } \\
\text { PA in older adults }\end{array}$ & $\begin{array}{l}\text { Community- } \\
\text { dwelling adults } \\
\text { aged } \geq 55 \text { years } \\
(1208)\end{array}$ & $\begin{array}{l}\text { Critically } \\
\text { low }\end{array}$ & Not assessed \\
\hline $\begin{array}{l}\text { Larsen et al } \\
\text { (2019) [23] }\end{array}$ & $\begin{array}{l}\text { Systematic review } \\
\text { and meta-analysis }\end{array}$ & $\begin{array}{l}21 \text { studies: } 20 \text { RCTs, } \\
1 \text { RCT with crossover } \\
\text { design }\end{array}$ & $\begin{array}{l}\text { To estimate the effect of } \\
\text { PAM }^{\mathrm{e}} \text {-based interventions } \\
\text { on PA behavior }\end{array}$ & $\begin{array}{l}\text { Adults aged } \geq 65 \\
\text { years }(2783)\end{array}$ & High & $\begin{array}{l}\text { Cochrane Risk of } \\
\text { Bias Tool (v2.0): } \\
\text { high risk }(\mathrm{n}=6) \text {, } \\
\text { moderate risk } \\
(\mathrm{n}=10), \text { low risk } \\
(\mathrm{n}=5)\end{array}$ \\
\hline $\begin{array}{l}\text { Muellmann et al } \\
\text { (2018) [24] }\end{array}$ & Systematic review & $\begin{array}{l}20 \text { studies: } 18 \text { RCTs, } \\
2 \text { quasiexperimental } \\
\text { designs }\end{array}$ & $\begin{array}{l}\text { To compare the effective- } \\
\text { ness of eHealth interven- } \\
\text { tions promoting PA in older } \\
\text { adults }\end{array}$ & $\begin{array}{l}\text { Adults aged } \geq 55 \\
\text { years }(6671)\end{array}$ & Moderate & $\begin{array}{l}\text { Cochrane Risk of } \\
\text { Bias Tool: high } \\
\text { risk }(\mathrm{n}=8) \text {, moder- } \\
\text { ate risk }(\mathrm{n}=11) \text {, } \\
\text { low risk }(\mathrm{n}=1)\end{array}$ \\
\hline $\begin{array}{l}\text { Yerrakalva et al } \\
\text { (2019) [25] }\end{array}$ & $\begin{array}{l}\text { Systematic review } \\
\text { and meta-analysis }\end{array}$ & $\begin{array}{l}6 \text { studies ( } 5 \text { included } \\
\text { in meta-analysis): } 5 \\
\text { RCTs, } 1 \text { NRSI }^{\mathrm{f}}\end{array}$ & $\begin{array}{l}\text { To quantify the effect of } \\
\text { mHealth }^{\mathrm{g}} \text { app interventions } \\
\text { on sedentary time, PA, and } \\
\text { fitness }\end{array}$ & $\begin{array}{l}\text { Community- } \\
\text { dwelling adults } \\
\text { aged } \geq 55 \text { years } \\
(486)\end{array}$ & High & $\begin{array}{l}\text { GRADE }{ }^{\mathrm{h}} \text { assess- } \\
\text { ment: moderate- } \\
\text { certainty evidence } \\
\text { for PA and seden- } \\
\text { tary time; low-cer- } \\
\text { tainty evidence for } \\
\text { fitness }\end{array}$ \\
\hline
\end{tabular}

\footnotetext{
${ }^{\mathrm{a}} \mathrm{Quality}$ of the evidence as assessed by the systematic review authors.

${ }^{b}$ RCTs: randomized controlled trials.

${ }^{\mathrm{c}} \mathrm{PA}$ : physical activity.

${ }^{\mathrm{d}}$ Excluded from this overview based on AMSTAR assessment.

ePAM: physical activity monitor.

${ }^{f}$ NRSI: nonrandomized study of interventions.

$\mathrm{g}_{\text {mHealth: mobile health. }}$

${ }^{\mathrm{h}}$ GRADE: Grading of Recommendations, Assessment, Development and Evaluations.
}

\section{Results}

The search process is illustrated in Figure 1. We identified 472 potentially relevant articles, after removal of duplicates. Following title and abstract independent screening, 15 reviews remained for full-text screening by both reviewers. Reasons for exclusion are listed in Multimedia Appendix 3. Overall, 5 reviews were selected for inclusion. Of these, 3 were systematic reviews with meta-analyses that provided pooled estimates of the effect of the technologies reviewed, 1 was a systematic review with a narrative synthesis, and 1 was a narrative review that used systematic review methods (Cochrane guidelines) for search selection and data extraction. Study characteristics and quality assessments for each included review are presented in Table 1. There was 100\% agreement on AMSTAR-2 quality ratings without need for consensus discussions. Two of the reviews were rated as high quality and 2 as moderate quality. The quality of 1 review [22] was assessed as critically low, meaning that "the review should not be relied upon to provide an accurate and comprehensive summary of the available 
evidence" [19]. The review was not strictly a systematic review, although it followed a systematic approach, and this may have contributed to the poor AMSTAR-2 rating. This review is not discussed further. For completeness, details of this review are presented in Tables 1 and 2 .

Figure 1. PRISMA flow diagram of the inclusion process.
Because of the heterogeneity of methods, interventions, and outcomes, we were unable to undertake a meta-analysis of the reviews included.

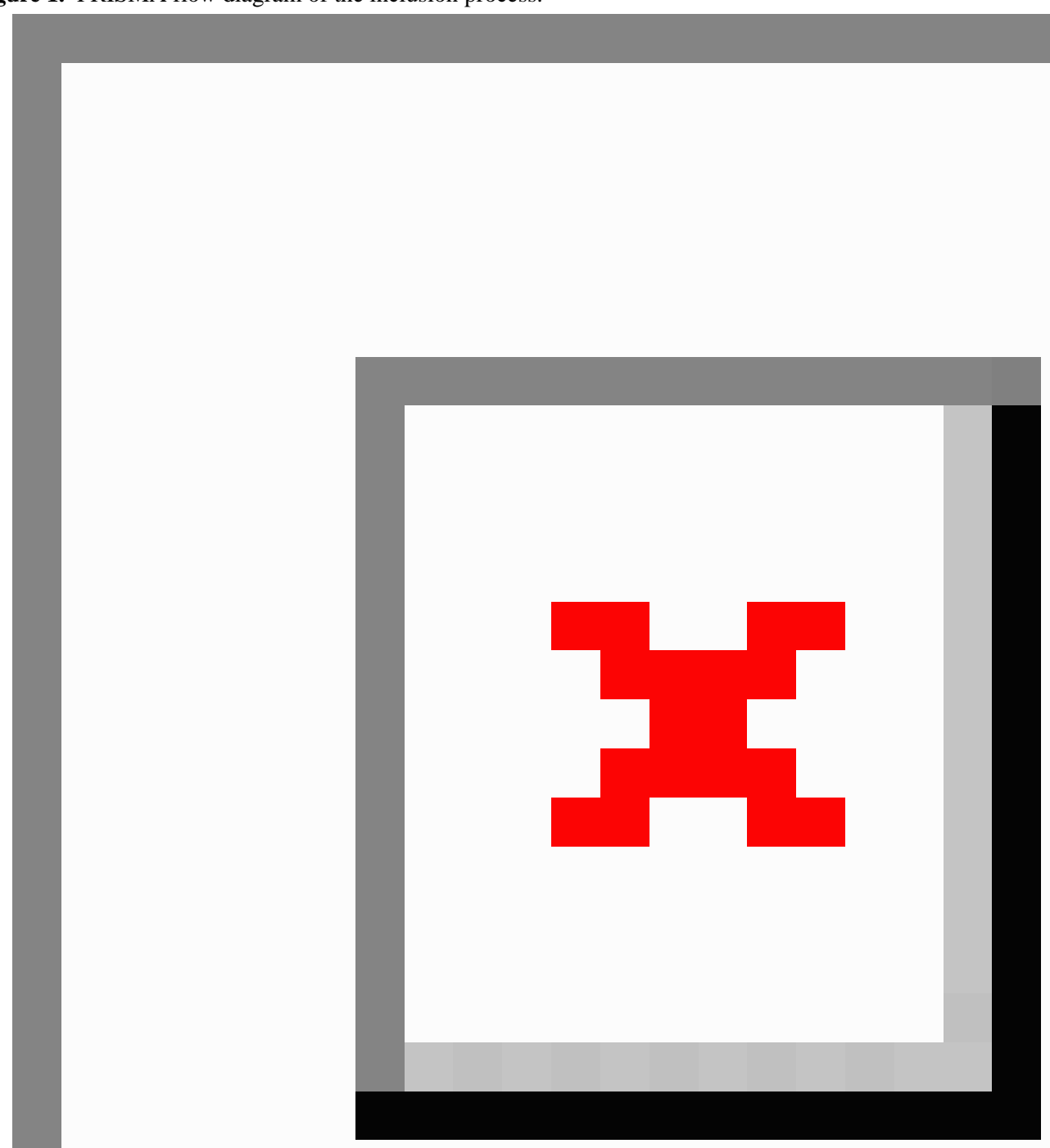


Table 2. Summary of review interventions, comparators, outcomes, and conclusion regarding intervention effectiveness.

\begin{tabular}{|c|c|c|c|c|}
\hline Author (year) & mHealth $^{\mathrm{a}}$ or eHealth intervention & Comparator or control & Key outcomes & Effectiveness of intervention \\
\hline $\begin{array}{l}\text { Cooper et al } \\
(2018)[21]\end{array}$ & $\begin{array}{l}\text { Wearable motion sensing technol- } \\
\text { ogy interventions (accelerometer } \\
\text { or pedometer) } \\
\text { designed to increase } \mathrm{PA}^{\mathrm{b}} \text {; dura- } \\
\text { tion range } \geq 6 \text { weeks, } \leq 52 \text { weeks }\end{array}$ & $\begin{array}{l}\text { Usual care or standard care, } \\
\text { waitlist control, or other ac- } \\
\text { tive comparator focused on } \\
\text { enhancing PA (eg, education- } \\
\text { al or behavioral interven- } \\
\text { tions) }\end{array}$ & $\begin{array}{l}\text { Change in PA behavior (min- } \\
\text { utes walking per day, steps per } \\
\text { day, proportion of participants } \\
\text { at activity goal) }\end{array}$ & $\begin{array}{l}\text { Statistically significant effect of } \\
\text { using accelerometers } \\
\left(\mathrm{SMD}^{\mathrm{c}}=0.43[95 \% \mathrm{CI} 0.19 \text { to }\right. \\
\left.\left.0.68, \mathrm{I}^{2}=1.6 \%{ }^{\mathrm{d}}\right]\right) \text {, but not pedome- } \\
\text { ters }(\mathrm{SMD}=0.17[95 \% \mathrm{CI}-0.08 \\
\left.\left.\text { to } 0.43, \mathrm{I}^{2}=37.7 \%\right]\right) \text { for increas- } \\
\text { ing PA levels }\end{array}$ \\
\hline $\begin{array}{l}\text { Jonkman et al } \\
(2018)^{\mathrm{e}}[22]\end{array}$ & $\begin{array}{l}\text { Computer, tablet, smartphone, or } \\
\text { smartwatch technology to pro- } \\
\text { mote PA or reduce sedentary be- } \\
\text { havior; duration range } \geq 4 \text { weeks, } \\
\leq 6 \text { months }\end{array}$ & $\begin{array}{l}\text { Usual practice, waitlist con- } \\
\text { trol, or other active compara- } \\
\text { tor (eg, pedometer, blinded } \\
\text { activity tracking) }\end{array}$ & $\begin{array}{l}\text { Objective assessment of the } \\
\text { amount of PA (eg, daily step } \\
\text { counts, minutes spent on PA) }\end{array}$ & $\begin{array}{l}\text { Positive short-term effect of in- } \\
\text { creased PA (ie, right after admin- } \\
\text { istering } \\
\text { the intervention), but lacking ev- } \\
\text { idence for long-term effects }\end{array}$ \\
\hline $\begin{array}{l}\text { Muellmann et al } \\
\text { (2018) [24] }\end{array}$ & $\begin{array}{l}\text { The main intervention compo- } \\
\text { nent delivered via computer (ie, } \\
\text { website, PDA, virtual advisor), } \\
\text { phone, or text messaging; dura- } \\
\text { tion range } \geq 4 \text { weeks, } \leq 24 \text { months }\end{array}$ & $\begin{array}{l}\text { Non-eHealth intervention } \\
\text { (eg, paper-pencil interven- } \\
\text { tion without eHealth compo- } \\
\text { nent, face-to-face consulta- } \\
\text { tion such as prescription of } \\
\text { PA by a physician, or exer- } \\
\text { cise in groups or with a per- } \\
\text { sonal trainer) or no interven- } \\
\text { tion }\end{array}$ & $\begin{array}{l}\text { PA assessed using objective } \\
\text { measures (eg, pedometer, ac- } \\
\text { celerometer), subjective mea- } \\
\text { sures (eg, PA diary, question- } \\
\text { naires), or a } \\
\text { combination of objective and } \\
\text { subjective methods }\end{array}$ & $\begin{array}{l}\text { Overall, the } 9 \text { studies that used } \\
\text { web-based interventions appear } \\
\text { to have beneficial effects on in- } \\
\text { creasing PA compared to various } \\
\text { comparators (no intervention or } \\
\text { paper-based interventions) in the } \\
\text { short-term (1- } 6 \text { months) with } \\
\text { small effect sizes in the range of } \\
0.20-0.31 \text {. }\end{array}$ \\
\hline $\begin{array}{l}\text { Yerrakalva et al } \\
(2019)[25]\end{array}$ & $\begin{array}{l}\text { mHealth app intervention deliv- } \\
\text { ered via smartphones or tablet } \\
\text { computers; in } 5 \text { of } 6 \text { studies, the } \\
\text { app synced with a wearable de- } \\
\text { vice (pedometers or wearable } \\
\text { smart device); duration range } \geq 3 \\
\text { months, } \leq 6 \text { months }\end{array}$ & $\begin{array}{l}\text { Modified dose of interven- } \\
\text { tion } \\
\text { (modified volume of inter- } \\
\text { vention or modified version } \\
\text { of same app), different app, } \\
\text { non-app intervention, or no } \\
\text { intervention }\end{array}$ & $\begin{array}{l}\text { PA (active minutes per day; } \\
\text { steps per day), physical fitness } \\
\text { (maximal oxygen uptake, 6- } \\
\text { minute timed walk, gait speed), } \\
\text { and sedentary time (\% seden- } \\
\text { tary time per day, sitting time } \\
\text { per day) }\end{array}$ & $\begin{array}{l}\text { Interventions may be associated } \\
\text { with increased PA (pooled mean } \\
\text { difference } 506 \text { steps/day [ } 95 \% \\
\left.\mathrm{CI}-80 \text { to } 1092, \mathrm{I}^{2}=80.5 \%\right] \text { ), de- } \\
\text { creased sedentary time } \\
\text { ( } \mathrm{SMD}=-0.49[95 \% \mathrm{CI}-1.02 \text { to } \\
\left.0.03, \mathrm{I}^{2}=0 \%\right] \text { ), and increased fit- } \\
\text { ness (SMD=0.31 [95\% CI }-0.09 \\
\left.\text { to } 0.70, \mathrm{I}^{2}=0 \%\right] \text { ) in trials } \leq 3 \\
\text { months and with increased PA } \\
\text { ( } 753 \text { steps/day) in trials } \geq 6 \\
\text { months. Results for all individual } \\
\text { outcomes revealed trends in the } \\
\text { same direction, but all results } \\
\text { were inconclusive as the CIs in- } \\
\text { cluded zero. }\end{array}$ \\
\hline
\end{tabular}

\footnotetext{
amHealth: mobile health.

${ }^{\mathrm{b}} \mathrm{PA}$ : physical activity.

${ }^{\mathrm{c}} \mathrm{SMD}$ : standardized mean difference.

${ }^{\mathrm{d}}$ Measure of heterogeneity.

${ }^{\mathrm{e}}$ Excluded from this overview based on AMSTAR assessment.

${ }^{f}$ PAM: physical activity monitor.

${ }^{g}$ MVPA: moderate-to-vigorous physical activity.

${ }^{\mathrm{h}}$ HRQoL: health-related quality of life.
} 


\section{Types of mHealth and eHealth Interventions}

An overview of the interventions, comparators, outcomes, and effectiveness of the interventions described in the reviews are presented in Table 2 . In 2 reviews, interventions were delivered via wearable motion sensing devices (eg, accelerometers or pedometers) [21,23]. In 1 review, interventions were delivered via apps on smartphones or tablets, and all but one of the included studies involved syncing the app to wearable devices
[25]. One review [24] included a mix of interventions, including computer-based (ie, websites, personal digital assistant, virtual advisor; $n=9)$, phone $(n=7)$, and text messaging $(n=4)$, with a separate narrative synthesis provided for each mode of intervention. The overall intervention duration for studies included in reviews ranged from 4 weeks to 2 years. All reviews reported on physical activity as a key outcome. Figure 2 presents a summary of evidence from meta-analyses for each intervention.

Figure 2. Summary of evidence from meta-analyses. Green indicates the intervention was effective, amber indicates there was no difference in the investigated comparison, grey indicates the evidence was inconclusive, and no color (blank) indicates the outcome was not assessed.

\begin{tabular}{|c|c|c|c|c|c|}
\hline Intervention & Author (year) & $\begin{array}{l}\text { Physical } \\
\text { activity }\end{array}$ & $\begin{array}{l}\text { Sedentary } \\
\text { time }\end{array}$ & $\begin{array}{l}\text { Physical } \\
\text { fitness or } \\
\text { capacity }\end{array}$ & $\begin{array}{l}\text { Moderate } \\
\text { to vigorous } \\
\text { physical } \\
\text { activity }\end{array}$ \\
\hline Accelerometers & $\begin{array}{l}\text { Cooper et al } \\
\text { (2018) [21] }\end{array}$ & & & & \\
\hline Pedometers & $\begin{array}{l}\text { Cooper et al } \\
(2018)[21]\end{array}$ & & & & \\
\hline $\begin{array}{l}\text { Physical Activity } \\
\text { Monitors }\end{array}$ & $\begin{array}{l}\text { Larsen et al } \\
\text { (2019) [22] }\end{array}$ & & & & \\
\hline Apps & $\begin{array}{l}\text { Yerrakalva et al } \\
\text { (2019) [23] }\end{array}$ & & & & \\
\hline
\end{tabular}

\section{Reviews Reporting Significant Effects of Interventions}

Significant effects of mHealth or eHealth interventions on physical activity outcomes were reported by 3 reviews.

Larsen et al [23] reviewed 21 studies on the effects of physical activity monitors (PAM) on physical activity, sedentariness, physical capacity, BMI, and self-reported health-related quality of life (HRQoL) compared to control interventions. Of these studies, 20 were RCTs with parallel group design, and 1 was a crossover RCT. Although 6 studies included samples with specific diagnoses, subgroup analysis revealed no significant differences across any of the outcomes in relation to diagnoses. Regarding the risk of bias, 5 studies were rated as having low risk of bias, 10 studies as medium risk, and 6 studies as high risk of bias. Results of a random effects meta-analysis on the effect of PAM intervention on physical activity found a moderate standardized mean difference (SMD) of $0.54(95 \%$ CI 0.34 to 0.73 ) in support of the PAM interventions, equivalent to about 1300 more steps per day. Furthermore, there was a small to moderate effect on moderate-to-vigorous physical activity equivalent to 8 more minutes activity per day (SMD $0.35,95 \%$ CI 0.15 to 0.52 ), favoring intervention. Heterogeneity was high for both comparisons. The pooled effects for time spent sedentary, physical capacity, BMI, and self-reported HRQoL were not significant. Effects are not reported in relation to length of the intervention, but sensitivity analysis found that intervention length was not significantly correlated with the effect size for any outcomes. Overall, the quality of the evidence was judged as low to moderate due to unexplained heterogeneity, publication bias, and imprecision. However, the authors conclude that PAM-based interventions are safe and feasible for use in older adult populations.

Cooper et al [21] reviewed 9 RCTs that investigated the effect of accelerometer and pedometer use on physical activity in older adults, 8 of which were included in the meta-analysis. Most studies $(n=6)$ were judged to be at high risk of bias, 2 were unclear, and 1 was considered to be at low risk of bias. Pooled results from 4 studies investigating the effect of accelerometers revealed small to moderate positive effects on physical activity (SMD 0.43, 95\% CI 0.19 to 0.68). Pooled results from 4 studies investigating pedometers revealed no statistically significant effect on physical activity (SMD $0.22,95 \%$ CI -0.08 to 0.51 ). Overall, shorter duration accelerometer interventions appeared to have a larger effect, but intervention duration and individual study estimates were variable. Adherence to the intervention was reported in 5 of the 9 included studies and was high on average $(\geq 80 \%)$. The authors concluded that higher step detection accuracy in accelerometers may explain why feedback from accelerometers was found to increase levels of physical activity, whereas pedometers did not, but caution that the high risk of bias found in most studies limits conclusions that can be drawn from these findings.

Muellmann et al [24] reviewed 20 studies comparing the effects of eHealth interventions on physical activity in older people ( $\geq 55$ years). Only 1 study was assessed as having low risk of bias. Heterogeneity in intervention, mode of delivery, duration, outcome assessments, and comparator groups precluded meta-analysis. There were 18 RCTs and 2 quasiexperiments. Website-based interventions were used in 9 studies. These studies overall appear to have beneficial effects on increasing physical activity compared to comparators (no intervention or 
paper-based interventions) in the short-term (1-6 months) with small effect sizes in the range of $0.20-0.31$. Of the 7 studies using telephone-based interventions (health education, telephone fitness sessions, and advice), 3 studies reported no effect, while 4 reported effects of improved activity. Observed effects were most common over the shorter term. Of the 4 studies including text-messaging interventions, 3 reported positive effects of text messaging over periods up to 3 months but not beyond. The authors conclude that "eHealth interventions can effectively promote PA in older adults aged 55 years and above when compared to no intervention control groups at least in the short term." Interventions that are theory-based were more effective regardless of intervention mode, and greater engagement was associated with effect, but participants seldom reached intended exercise dose. The authors urge caution, as the risk of bias in the studies reviewed was high to moderate and there was great heterogeneity in intervention mode, content, and duration.

\section{Reviews Reporting Inconclusive Effects of Interventions}

One of the reviews, by Yerrakalva et al [25], found no significant effects of app-based interventions on physical activity outcomes. The review included 6 studies (5 RCTs); studies appear underpowered, with all but 1 having total sample sizes $<65$ and intervention groups $<25$ participants. For the RCTs, risk of bias was judged to be low. The pooled analyses reported the following: for physical activity, average increases of 506 steps per day over 3 months and 753 steps per day over 6-12 months; for sedentary behavior, reductions in sedentary time at 3 months and 6 months; for physical fitness, small increases in fitness up to 3 months expressed in a number of different ways (gait speed, timed walk, $\mathrm{VO}_{2} \max$ ). Results reveal trends in the same direction for an effect of the apps but have to be judged as inconclusive as confidence intervals included zero. Features that appeared to be common to apps demonstrating improvement trends included syncing to smartwatches or activity monitors and behavior change techniques including goal setting, self-monitoring, instructions for use, social rewards, and combining the app with professional support.

\section{Discussion}

We undertook a rapid review of systematic reviews to assess the evidence for mHealth or eHealth interventions in the promotion of physical activity among older people. We initially included 5 reviews but excluded 1 (critically low quality) from the overview. We were unable to undertake meta-analysis of the reviews because of the heterogeneity of the methods, interventions, and outcomes. Three reviews [21,23,24], 2 of which included meta-analyses, found that eHealth approaches (activity monitors, web-based interventions) improved physical activity outcomes. One review and meta-analysis [25] reported trends toward an intervention effect; however, results were inconclusive. Although risk of bias was judged to be low in the studies included in the review, they appeared underpowered, with small total and group sample sizes, potentially explaining why no significant effects were found. Overall, there is evidence from 3 moderate- to high-quality systematic reviews to support the effectiveness of mHealth or eHealth approaches in increasing physical activity, at least over the short term. Due to reported risk of bias in the studies included in the reviews, the overall quality of this evidence is judged as low to moderate.

The reviews identified several components of successful interventions that align with behavior change techniques known to increase motivation and facilitate behavior modification [26]. Most of the studies involved elements of self-monitoring and feedback, either in the form of apps or wearable devices. The provision of real-time feedback on individuals' levels of physical activity was associated with significant increases in the behavior [24], and the implementation of motivational tools such as self-monitoring and feedback as a means of positively impacting levels of physical activity, goal attainment, and adherence has previously demonstrated success [21]. Interventions that were theory-based were more effective, and effect was associated with greater engagement regardless of the mode of intervention [24]. Although Yerrakalva et al [25] determined the effect of the intervention was inconclusive, they reported on the common features of the studies that found app interventions to be effective. These included self-monitoring, goal setting, clear instruction on how to perform the behavior, and social and professional support. Support from professionals may be particularly important in encouraging engagement and adherence to home exercise. A review on home-based, nontechnology physical activity interventions in older adults [27] found that contacting individuals by phone in order to provide support was a good alternative to onsite supervision. They reported strong evidence, based on 3 studies, indicating that direct remote contact had positive effects on physical activity and capacity measures, to a similar extent as supervised training.

An important consideration for mHealth or eHealth interventions concerns the practicalities of implementing technological solutions, especially when users have limited experience of using such devices [28]. This is an important point to keep in mind for the older and disadvantaged sectors of the population, whom we already know are likely to have less experience of technologies [29]. Consideration must be given to the "digital divide" that may result from socioeconomic status, age, geographic location, and cultural factors [28]. Technologies need to provide activity interventions that fit in with older peoples' lifestyles and expectations and offer tailored interventions taking account of individual preferences and capabilities. A review of older adults' perceptions of technologies [30] found that one size does not fit all and technologies need to be tailored to individual need. Intrinsic factors related to older adults' attitudes towards technologies centered around control, independence, and perceived need or requirement for safety are all important for motivation to use the technologies. Extrinsic factors identified were related to usability, feedback gained from technology, and costs. If older people are to use technologies, the positive benefits need to be emphasized and clearly recognizable, including how the technology promotes independence. Technologies need to be perceived as reliable and effective if they are to engender long-term use. Acceptability of technology and adherence to the interventions were not key outcomes in any of the reviews included in our review. Even so, adherence was high on average in 5 of the studies included in 1 review [21]. Wearable devices 
such as accelerometers and pedometers are feasible for use with older adult populations, with devices attached to the wrist or ankle being most commonly accepted in older groups [31].

This rapid review of reviews used rigorous systematic methods in the search of the literature and the assessment of review quality, and we excluded reviews of low methodological quality. Nevertheless, reviews of reviews can be limited as they face the challenge of synthesizing information in the presence of inevitable heterogeneity. This had a clear effect in this review resulting in our inability to meta-analyze results from previous reviews. Even so, this type of review allows a greater scope for generality in research findings and provides an accessible summary of evidence to support decision making by health care professionals or policy makers [14].

In conclusion, the use of mHealth or eHealth interventions with older people may be effective in increasing physical activity and physical fitness and decreasing sedentary time, over the short term. However, the evidence is currently not conclusive. These findings are in line with those relating to mHealth interventions to increase activity and reduce sedentary behaviors for all age groups [10]. Furthermore, our review suggests that interventions that are theory-based and include behavior change techniques, clear instructions, and social and professional support may be more effective than those that do not. When introducing new technologies such as apps to older people, the steep learning curve older people may experience must be recognized and support supplied to help them become familiar with the technology. Given the ongoing crisis caused by COVID-19 and the challenges we face as we reorganize services in a post-COVID-19 world, there is clearly great potential for digitalization of services for older people, although differences in uptake could exacerbate health inequalities if access is not made available to all groups. The evidence for the effectiveness of mHealth or eHealth provision of interventions to support and promote physical activity among older people is still in its infancy, but nonetheless promising. Future research requires high-quality RCTs comparing different modes of delivery, but implementation may require faster turnaround and should therefore be rigorously evaluated.

\section{Acknowledgments}

This work was supported by the National Institute for Health Research through the NIHR Policy Research Unit in Older People and Frailty, NIHR Applied Research Collaboration Greater Manchester, and a NIHR Senior Investigator Award to CT. The views expressed are those of the authors and not necessarily those of the NHS, the NIHR, the Department of Health and Social Care, or its partner organizations.

\section{Conflicts of Interest}

None declared.

\section{Multimedia Appendix 1}

Search terms.

[PDF File (Adobe PDF File), 100 KB-Multimedia Appendix 1]

\section{Multimedia Appendix 2}

Data extracted.

[PDF File (Adobe PDF File), 59 KB-Multimedia Appendix 2]

\section{Multimedia Appendix 3}

Excluded full text articles with reasons. [PDF File (Adobe PDF File), 109 KB-Multimedia Appendix 3]

\section{References}

1. Sun F, Norman IJ, While AE. Physical activity in older people: a systematic review. BMC Public Health 2013 May 06;13(1):449 [FREE Full text] [doi: 10.1186/1471-2458-13-449] [Medline: 23648225]

2. Blodgett J, Theou O, Kirkland S, Andreou P, Rockwood K. The association between sedentary behaviour, moderate-vigorous physical activity and frailty in NHANES cohorts. Maturitas 2015 Feb;80(2):187-191. [doi: 10.1016/j.maturitas.2014.11.010] [Medline: 25542406]

3. Banks J, Breeze E, Lessof C, Nazroo J. Mortality and healthy life expectancy. Living in the 21st Century: Older People in England.: The Institute for Fiscal Studies; 2008. URL: https://www.ifs.org.uk/elsa/report08/elsa w3.pdf [accessed 2020-12-12]

4. Blair SN, Morris JN. Healthy hearts - and the universal benefits of being physically active: physical activity and health. Ann Epidemiol 2009 Apr;19(4):253-256. [doi: 10.1016/j.annepidem.2009.01.019] [Medline: 19344864]

5. Koščak Tivadar B. Physical activity improves cognition: possible explanations. Biogerontology 2017 Aug 10;18(4):477-483. [doi: 10.1007/s10522-017-9708-6] [Medline: 28492999] 
6. Arem H, Moore SC, Patel A, Hartge P, Berrington de Gonzalez A, Visvanathan K, et al. Leisure time physical activity and mortality: a detailed pooled analysis of the dose-response relationship. JAMA Intern Med 2015 Jun 01;175(6):959-967 [FREE Full text] [doi: 10.1001/jamainternmed.2015.0533] [Medline: 25844730]

7. Sherrington C, Fairhall N, Wallbank G, Tiedemann A, Michaleff ZA, Howard K, et al. Exercise for preventing falls in older people living in the community. Cochrane Database Syst Rev 2019 Jan 31;1:CD012424 [FREE Full text] [doi: 10.1002/14651858.CD012424.pub2] [Medline: 30703272]

8. Bateman DR, Srinivas B, Emmett TW, Schleyer TK, Holden RJ, Hendrie HC, et al. Categorizing Health Outcomes and Efficacy of mHealth Apps for Persons With Cognitive Impairment: A Systematic Review. J Med Internet Res 2017 Aug 30;19(8):e301 [FREE Full text] [doi: 10.2196/jmir.7814] [Medline: 28855146]

9. Eysenbach G. What is e-health? J Med Internet Res 2001 Jun 18;3(2):E20 [FREE Full text] [doi: 10.2196/jmir.3.2.e20] [Medline: 11720962$]$

10. Direito A, Carraça E, Rawstorn J, Whittaker R, Maddison R. mHealth Technologies to Influence Physical Activity and Sedentary Behaviors: Behavior Change Techniques, Systematic Review and Meta-Analysis of Randomized Controlled Trials. Ann Behav Med 2017 Apr 18;51(2):226-239. [doi: 10.1007/s12160-016-9846-0] [Medline: 27757789]

11. Lyons EJ, Swartz MC, Lewis ZH, Martinez E, Jennings K. Feasibility and Acceptability of a Wearable Technology Physical Activity Intervention With Telephone Counseling for Mid-Aged and Older Adults: A Randomized Controlled Pilot Trial. JMIR Mhealth Uhealth 2017 Mar 06;5(3):e28 [FREE Full text] [doi: 10.2196/mhealth.6967] [Medline: 28264796]

12. Gell N, Rosenberg D, Demiris G, LaCroix AZ, Patel KV. Patterns of technology use among older adults with and without disabilities. Gerontologist 2015 Jun;55(3):412-421 [FREE Full text] [doi: 10.1093/geront/gnt166] [Medline: 24379019]

13. Khangura S, Konnyu K, Cushman R, Grimshaw J, Moher D. Evidence summaries: the evolution of a rapid review approach. Syst Rev 2012 Feb 10;1(1):10 [FREE Full text] [doi: 10.1186/2046-4053-1-10] [Medline: 22587960]

14. Hunt H, Pollock A, Campbell P, Estcourt L, Brunton G. An introduction to overviews of reviews: planning a relevant research question and objective for an overview. Syst Rev 2018 Mar 01;7(1):39 [FREE Full text] [doi:

10.1186/s13643-018-0695-8] [Medline: 29490699]

15. Smith V, Devane D, Begley CM, Clarke M. Methodology in conducting a systematic review of systematic reviews of healthcare interventions. BMC Med Res Methodol 2011 Feb 03;11(1):15 [FREE Full text] [doi: 10.1186/1471-2288-11-15] [Medline: 21291558]

16. Roy Rosenzweig Center for History and New Media. Zotero. 2020. URL: https://www.zotero.org/ [accessed 2020-12-14]

17. Ouzzani M, Hammady H, Fedorowicz Z, Elmagarmid A. Rayyan-a web and mobile app for systematic reviews. Syst Rev 2016 Dec 05;5(1):210 [FREE Full text] [doi: 10.1186/s13643-016-0384-4] [Medline: 27919275]

18. Pollock M, Fernandes R, Becker L. Chapter V: Overviews of Reviews. In: Higgins J, Thomas J, Chandler J, editors. Cochrane Handbook for Systematic Reviews of Interventions Version 6.0 (Updated March 2020). London: Cochrane; 2020.

19. Shea BJ, Reeves BC, Wells G, Thuku M, Hamel C, Moran J, et al. AMSTAR 2: a critical appraisal tool for systematic reviews that include randomised or non-randomised studies of healthcare interventions, or both. BMJ 2017 Sep 21;358:j4008 [FREE Full text] [doi: 10.1136/bmj.j4008] [Medline: 28935701]

20. AMSTAR. 2017. URL: www.amstar.ca [accessed 2020-12-12]

21. Cooper C, Gross A, Brinkman C, Pope R, Allen K, Hastings S, et al. The impact of wearable motion sensing technology on physical activity in older adults. Exp Gerontol 2018 Oct 02;112:9-19 [FREE Full text] [doi: 10.1016/j.exger.2018.08.002] [Medline: $\underline{\text { 30103025] }}$

22. Jonkman NH, van Schooten KS, Maier AB, Pijnappels M. eHealth interventions to promote objectively measured physical activity in community-dwelling older people. Maturitas 2018 Jul;113:32-39. [doi: 10.1016/j.maturitas.2018.04.010] [Medline: 29903646]

23. Larsen RT, Christensen J, Juhl CB, Andersen HB, Langberg H. Physical activity monitors to enhance amount of physical activity in older adults - a systematic review and meta-analysis. Eur Rev Aging Phys Act 2019 May 4;16(1):7 [FREE Full text] [doi: 10.1186/s11556-019-0213-6] [Medline: $\underline{31073341]}$

24. Muellmann S, Forberger S, Möllers T, Bröring E, Zeeb H, Pischke CR. Effectiveness of eHealth interventions for the promotion of physical activity in older adults: A systematic review. Prev Med 2018 Mar;108:93-110. [doi: 10.1016/j.ypmed.2017.12.026] [Medline: 29289643]

25. Yerrakalva D, Yerrakalva D, Hajna S, Griffin S. Effects of Mobile Health App Interventions on Sedentary Time, Physical Activity, and Fitness in Older Adults: Systematic Review and Meta-Analysis. J Med Internet Res 2019 Nov 28;21(11):e14343 [FREE Full text] [doi: 10.2196/14343] [Medline: $\underline{\text { 31778121] }}$

26. Michie S, Richardson M, Johnston M, Abraham C, Francis J, Hardeman W, et al. The behavior change technique taxonomy (v1) of 93 hierarchically clustered techniques: building an international consensus for the reporting of behavior change interventions. Ann Behav Med 2013 Aug 20;46(1):81-95. [doi: 10.1007/s12160-013-9486-6] [Medline: 23512568]

27. Geraedts H, Zijlstra A, Bulstra SK, Stevens M, Zijlstra W. Effects of remote feedback in home-based physical activity interventions for older adults: a systematic review. Patient Educ Couns 2013 Apr;91(1):14-24. [doi:

10.1016/j.pec.2012.10.018] [Medline: 23194823] 
28. Carter DD, Robinson K, Forbes J, Hayes S. Experiences of mobile health in promoting physical activity: A qualitative systematic review and meta-ethnography. PLoS One 2018 Dec 17;13(12):e0208759 [FREE Full text] [doi: 10.1371/journal.pone.0208759] [Medline: $\underline{\text { 30557396] }}$

29. Matthews K, Nazroo J, Marshall A. Digital inclusion in later life: cohort changes in internet use over a ten-year period in England. Ageing and Society 2018 Aug 02;39(9):1914-1932. [doi: 10.1017/s0144686x18000326]

30. Hawley-Hague H, Boulton E, Hall A, Pfeiffer K, Todd C. Older adults' perceptions of technologies aimed at falls prevention, detection or monitoring: a systematic review. Int J Med Inform 2014 Jun;83(6):416-426. [doi: 10.1016/j.ijmedinf.2014.03.002] [Medline: 24798946]

31. de Bruin ED, Hartmann A, Uebelhart D, Murer K, Zijlstra W. Wearable systems for monitoring mobility-related activities in older people: a systematic review. Clin Rehabil 2008 Oct;22(10-11):878-895. [doi: 10.1177/0269215508090675] [Medline: $\underline{18955420}$ ]

\author{
Abbreviations \\ HRQoL: health-related quality of life \\ METs: metabolic equivalents of task \\ PAM: physical activity monitor \\ PRISMA: Preferred Reporting Items for Systematic Reviews and Meta-Analyses \\ RCT: randomized controlled trial \\ SMD: standardized mean difference
}

Edited by G Eysenbach; submitted 06.07.20; peer-reviewed by J Alvarez Pitti, AS Aslam; comments to author 04.09.20; revised version received 18.09.20; accepted 29.10.20; published 29.12.20

Please cite as:

McGarrigle L, Todd C

Promotion of Physical Activity in Older People Using mHealth and eHealth Technologies: Rapid Review of Reviews

J Med Internet Res 2020;22(12):e22201

URL: http://www.jmir.org/2020/12/e22201/

doi: $\underline{10.2196 / 22201}$

PMID: 33372894

CLisa McGarrigle, Chris Todd. Originally published in the Journal of Medical Internet Research (http://www.jmir.org), 29.12.2020. This is an open-access article distributed under the terms of the Creative Commons Attribution License (https://creativecommons.org/licenses/by/4.0/), which permits unrestricted use, distribution, and reproduction in any medium, provided the original work, first published in the Journal of Medical Internet Research, is properly cited. The complete bibliographic information, a link to the original publication on http://www.jmir.org/, as well as this copyright and license information must be included. 